\title{
Problem and Problem-solving Route Search on Current Chinese Wushu Industry
}

\author{
Zhihong Li, Zhongqiu Hu \\ College of physical education, Hubei Normal University, Huangshi Hubei, 435002, China
}

Keywords: Chinese Wushu Industry, Problems, Problem-solving Route.

\begin{abstract}
Chinese Wushu has enjoyed a reputation in the international community, through the progressive development in recent years, it has formed a Wushu events and Wushu tourism-based industry model. In the market economy environment, the benefits become the guidance tools of people's ideas and activities, in this context, if Wushu still takes the spirit of martial arts output as the development direction, it cannot arouse people's attention, and it will also hinder its continued development. So Wushu career change must be appropriate to the type of business. Although the development of Wushu industry has begun to take shape, but it still has many problems to be solved in the industrial structure, organization and policy. The article will analyze problems of Wushu industry in different industries direction and propose appropriate solutions path.
\end{abstract}

\section{Introduction}

Chinese martial arts has been the spirit of the output as the main direction of development, and therefore must have its own position on the international stage. But in the context of a market economy, this purely spiritual food has been unable to support the career development of martial arts, martial arts career so must follow the development trend of the times, and gradually move toward industrialization, economic development road. The transition process will face many problems, the next martial arts industry in China in the presence of the paper will solve the problem and path analysis.

\section{Problems in Chinese Wushu Industry Development}

\section{Problems in Wushu Entertainment Industry.}

Increasingly rich material life today, people's spiritual and psychological quality standards higher and higher. Martial arts in order to better development, must be based on people's needs as the focus, to break the traditional career development sequence, rearrange integration ${ }^{[1]}$. Wushu has a significant role in fitness, cultivation and entertainment, so this is one of the development trend of martial arts industry. Our fitness program for the development of martial arts provides an effective external environment. In the digital age, martial arts is no longer a means of maintaining security, but gradually transformed into self-cultivation, an effective way to physical health, longevity and enjoy entertainment and other aspects. But so far Wushu theoretical research on human health is relatively small, there is no data to substantiate the martial arts or literature on human health effects of specific effects and mechanism. So now Martial Arts Theory missing phenomenon in fitness, it is difficult to convince people. Second, the fitness value is also reflected in martial arts fitness Sanda, taekwondo and gym, but because of its project in the form of a single, very few people capable of long-standing practice, so that the martial arts promotion is limited.

\section{Problems in Wushu Training Industry.}

Martial arts training industry is an extension of the fitness and martial arts Wushu competition of the industry, but also to carry out basic cause of the martial arts, so martial arts training in the development of its industry for industrial and economic development pillar. Development of martial arts training industry for the industry to be able to attract more consumers to enhance its market share, but also lay a good foundation for personnel training martial arts industry. Current momentum martial arts training industry development better, martial arts training schools around the constant increase in the number of enrolled students is also on the rise, but behind the good growth prospects but also a lot 
of hidden problems. First, a martial arts instructor of martial arts accomplishment itself is not high, a lot of martial arts training school coaches do not even have teaching qualifications, but there is a big difference with a martial arts school martial arts instructor qualifications, our country is also lack of information on martial arts teacher certification system. Second, the government has some problems to support policies and management of a martial arts school, the government in many areas simply impose martial arts school taxes, but they ignore the policy of a martial arts school, economic empowerment and standardized system of management, so that the martial arts school can not get the Government's guidance, in general, it is the government's chaotic management problems. Third, the martial arts school running mostly individual contractors, the inevitable supremacy of the interests of the phenomenon in the school management process, resulting in outdated school facilities, schools and sports venues is limited, it is difficult to give students effective learning and training issues . Fourth, the quality of personnel management of the school is relatively low, only focus on the students' martial arts skill instruction, ignoring the students Takenori education.

\section{Problems in Wushu Industry.}

Wushu Wushu tourism industry is also a major feature of the industry. Some use martial arts Wushu birthplace of tourism resources to carry out, so dig out martial arts tourism function. But from the point of view of tourism development of martial arts, martial arts based mainly in the better areas, regional branches scattered, uneven, and even martial arts area has a good foundation in the operation of tourism is also a lack of Tourist Resources Development and environmental awareness, and lack of management system, it is difficult to form a standardized organization, tourist attractions are often fragmented, leading to the market management confusion, it is difficult to adjust the system and constraints. At the same time there is a lack of tourism characteristic products and tourism monotonous phenomenon.

\section{Problems in Wushu Products Industry.}

Martial arts supplies martial arts can also be zoned to the production of material goods industries, product quality directly affects consumers' purchasing power and the visual impression [2]. Through the development of martial arts supplies martial arts industry to promote investment in research, thus creating a variety of martial arts products. Development of martial arts supplies industry has low entry advantage, the operator does not need to have martial arts foundation and experience, as long as there is sufficient economic resources to be able to participate in the operation. So in the martial arts influence gradually increase the conditions of China's martial arts supplies industry is also gradually showing scale, in large supermarkets, sporting goods store can see the shadow of martial arts supplies and distribution in the form of columns, we can see it market share is more substantial. With the increase in the share of martial arts supplies martial arts supplies and large companies set up, we see the development prospects of martial arts supplies industry, but China's current martial arts supplies market is still in a state of disorder, lack of scientific and effective management system. At the same time, the development of martial arts supplies industry also need to pay attention to the classification of the project development and the development of standards. There are many types of martial arts, different types of martial arts martial arts supplies needed will be different, so the development of martial arts supplies needed for different projects to create different martial arts martial arts supplies. To address this issue, martial arts clothing enterprises can be based on different characteristics of boxing, and with reference to China's ancient martial arts to develop special clothing clothing, but clothing martial arts athletes and referees have to be different. And different martial arts, martial arts school style may also be appropriate to make adjustments. So the existence of martial arts supplies martial arts supplies industry is low grade, large-scale sales and the lack of scientific and technological content, low-quality products is not complete and other issues. In the sales channels, advertising propaganda is not strong, single way.

\section{Development Route of Chinese Wushu Industry}

\section{Wushu Fitness Business Development Path.}

a. Focus on the development of the martial arts community. Government needs to guide community awareness in the context of fitness, active in martial arts fitness and entertainment 
projects, and strive to achieve the residents are able to master a set of martial arts boxing, martial arts face in order to expand sales of products, and thus make martial arts fitness and entertainment market further extension.

b. Learn from foreign advanced management mode. And other Chinese Wushu fitness club and gym unreasonable management mode, leading to confusion in the market, can not effectively scale. So our martial arts fitness and recreation management needs to actively learn from foreign management, combined with the development of the local martial arts, continuously expand the sports fitness and recreation services, and gradually increase market share in the martial arts industry.

c. Strengthening Wushu Research. In addition to the combination of Chinese Wushu Research Thought of Spiritual Philosophy and Confucianism, but also we need to further study the martial arts from a scientific point of view combined with modern sporting spirit. Make martial arts more in line with contemporary human cognition. In the exercise of simple, physical appearance but also it has a certain fitness effect.

In short, martial arts fitness and entertainment industry requires from multiple angles to study and explore, and dialectical use of Western martial arts management, combined with our martial arts own characteristics, so martial arts fitness and entertainment features to adapt to different ages, different classes, different professional crowd. Meanwhile, in view of the modern pursuit of beauty more and more, the development of martial arts fitness and entertainment industry also needs to take full account of the "beauty" of elements, focusing on physical beauty of martial arts, to meet the aesthetic needs of people [3]. And to strengthen the study of martial arts theory, practice martial arts to guide people through scientific theory, so that people can get practical gain from martial arts practice, and thus the true love of martial arts fitness activities.

\section{Wushu Training Industry Development Path.}

a. The advent of commodity economy, people's attitudes and values to change. People's careers, future plans and even develop their own next generation are aimed at the economic benefits of good industry. So martial arts training propaganda must not only to physical fitness, self-cultivation, etc. as a gimmick, but also need to strengthen the analysis of the economic value of martial arts, martial arts training so as to enhance awareness of the recognition.

b. Wushu coaches standardized management. First, to strengthen the qualifications of Wushu Coaches approval, required to perform martial arts instructor must go through martial arts training system, and achieved grade and vocational certificates. Study abroad personnel must obtain the appropriate level of proof before they can be put to martial arts instructor industries. Second, strict martial arts and martial arts school for approval. Wushu or martial arts school approval required refinement, including martial arts and martial arts school field trips, the qualification and so on. Advertising is consistent with the actual situation to do, is strictly prohibited fraud, use of false advertising to deceive student enrollment and so on. At the same time, ensure that the martial arts or martial arts school teaching facilities to meet the teaching requirements. Also, emphasize student Takenori cultivation. Members set up a special monitoring body martial arts institutions, bodies by the person in charge of government officials, personnel Wushu Association and various martial arts schools to compose, martial arts oversight bodies not only to set up effective monitoring of the situation in martial arts schools, but also through the exchange to improve the martial arts training as well as experience in operating a school. Approval is not prohibited by the school office.

c. Improve Wushu Training Market Management. After martial arts school fees for unified management and strict control, martial arts schools as well as the specific amount of the fees required to report to the local relevant departments to determine the charges to meet local prices, the price can be developed. At the same time teaching martial arts teaching content should also be strict management to ensure a good fit for practice teaching content of the crowd, and to ensure that the content of health education, and practical.

\section{Wushu Tourism Industry Development Path.}

Martial tourism that is a way to combine martial arts and tourism development, both to increase the influence of martial arts, it is possible to develop rich tourism resources. Wushu development of tourism needs to be analyzed from two aspects, first of all, martial arts attractions development 
strategy. The government should increase Wushu attractions governance, strengthen tourism management martial arts, for some non-standard product or tourist attractions for rectification, removal and ban other treatment, and arbitrary charges of fraud tourist attractions phenomena key management, thus creating a civilization, rich in culture martial resort ${ }^{[4]}$. Wushu martial arts and cultural landscape to protect forensic scene intact, this is not only a selling point to attract tourists, but also China's cultural heritage. At the same time to strengthen the tourism promotion of martial arts, martial arts through the organization of seminars and other activities to raise awareness attractions also created a classic in wushu martial arts attractions, and through tour, organized by the authority of training activities to achieve ad Effect. Second, pay attention to the training of tourism personnel in the martial arts. Martial tourist attractions guide not only need to have the basic skills to guide, but also a deep understanding of martial arts, able to skillfully to introduce visitors to the knowledge of martial arts, where necessary, visitors can also practice a set of boxing, thus creating a good martial arts atmosphere.

\section{Wushu Product Industry Development Path.}

Martial Arts in our country with the development of the history of thousands of years, whether Culturally or from the martial effectiveness that its development equipment industry has a wealth of resources, you can extend martial arts supplies of style and functionality through continuous development ${ }^{[5]}$. Situation such as martial arts tourism products, audio and video discs, crafts, martial arts supplies but now is showing: martial arts supplies a single structure, the quality is not high, low technology content, to meet the psychological needs of consumers is not strong. So we need to increase efforts in Wushu, Wushu Association jointly developed by the different wushu dress and supplies, and the different roles people should also have the same item to distinguish between different colors and styles. Countries and relevant departments to pass legislation to regulate martial arts supplies market, improve the quality and grades of martial arts supplies, martial arts add value to the product, open the path of martial arts supplies sales, establish brand awareness. Finally, open up sales channels and promotional merchandise, two-way sales online and offline and multi-channel publicity through leaflets, television, Internet and other media.

\section{Conclusion}

In summary, the cause of martial arts is a traditional industry, but it has been standing in the martial spirit of the international stage, in a market economy and commodity economy in the background, it has been difficult to support the development of the spirit of martial arts martial arts industry, to promote martial arts and must be the times, seek industrialization, economic-oriented approach to development. However, due to the development of Wushu industry a short time, there are still many imperfections, the government, Wushu Association and martial arts heritage and enthusiasts work together to gradually improve in the martial arts industry issues, and promote the rapid development of martial arts industry.

\section{References}

[1] Wu Min, Yang Shaoxiong. Chinese Wushu Industry and Its Creative Ideas Hotspot Dialysis, Journal of Putian University, 2014,21 (2): 103-108.

[2] Wu Min, Yang Shaoxiong. Chinese Wushu Industry and Its Creative Ideas Hotspot Dialysis, Physical Sciences, 2014,18 (5): 6-10.

[3] Lee Benyi.Chinese Wushu Industrial Structure and Industrial Development Advantages of Henan Wushu, Journal of Liaoning Vocational College of Economics, 2015 (5): 10-12,49.

[4] Allah teng ChaoLu. Wushu Industry Market coordination Development Research, Journal of Jining Normal College, 2013,35 (1): 110-112.

[5] Cai Yanguo. Chinese Wushu Industry Development Strategy, Statistics and Management, 2015 (8): 151-152. 